\title{
Changing perspectives in coastal dune management
}

\author{
Paul Rooney
}

Published online: 24 March 2010

(C) Springer Science+Business Media B.V. 2010

This special issue of the Journal of Coastal Conservation, Planning and Management (JCCPM) includes some of the thirty seven papers delivered at the international coastal dune conference 'Changing Perspectives in Coastal Dune Management' held between 31st March and the 3rd April 2008 in Liverpool, UK. The conference was organised by the UK Sand Dune and Shingle Network based in Liverpool Hope University, and attracted around 120 delegates from five continents. Keynote speakers were Professor Norbert P. Psuty, Rutgers University, United States of America, Professor Maurice Hoffmann, Ghent University, Belgium and Dr Pat Doody, National Coastal Consultants, United Kingdom.

Liverpool was the European Capital of Culture in 2008 and has strong coastal associations through its maritime history and situation on the Mersey estuary. Most notably, the city is immediately adjacent to the Sefton Coast, an internationally important dune system and the largest area of open sand dunes in England. The conference organisers at the UK Sand Dune and Shingle Network have a long association with the management of this dune coast, and the conference field trips made use of this local resource. Thanks are due to the site managers of this coastline for facilitating the field trips.

The conference themes addressed research and management practice around the following major topics in coastal dune management

- People and dunes

- Change and dynamics

- Naturalness

P. Rooney $(\triangle)$

UK Sand Dune and Shingle Network, Geography Department, Liverpool Hope University,

Hope Park,

Liverpool L16 9JD, United Kingdom

e-mail: rooneyp@hope.ac.uk
The conference themes appreciate dunes as a changing environment and that our values and attitudes to dunes also change. This creates a dynamic decision-making environment, and raises questions concerning what is required of coastal dune management. In many ways these issues and questions are not new, but the perspectives taken are new as change occurs. The conference sought to explore and influence these changing perspectives.

Dr. Pat Doody presented a revised 'Sand Dune Inventory of Europe' at the conference, and each delegate received a copy on $\mathrm{CD}$. This contained detailed reports of the sand dune resource for each country. The $\mathrm{CD}$ was produced with the support of Liverpool Hope University and copies are available to purchase through the offices of the Coastal and Marine Union (EUCC) based in Leiden, the Netherlands. The 'Sand Dune Inventory of Europe' is a growing knowledge base, the results of which may be accessed on-line via the Encora Coastal Portal at http://www.coastalwiki.org/ coastalwiki/European_Sand_Dune_Distribution. Without a thorough and up to date understanding of the distribution, extent, geomorphological type, vegetation, condition, use and value of our coastal dunes it is difficult to make robust and sustainable management decisions. More work is required to update and expand the Inventory, and readers are encouraged to participate in the on-line Wiki-based Inventory.

Over historical time it is possible to identify many approaches to dune management and some considerable changes in the perception and value of blowing sand (Rooney and Houston 2009). As the twentieth century progressed considerable effort was given to academic research to further our understandings of coastal dunes. Some of the notable works for the British Isles from this early period include Steers (1946), Salisbury (1952) and Ranwell (1972). At the same time new dune management practices were developed across Europe as the human values placed upon coastal dunes changed through, for instance, the development of the nature conservation movement. 
A watershed in European dune management thinking occurred in 1987 when the dynamic approach to dune management was given a platform at the symposium on dune management held in Leiden, the Netherlands. The event aimed to steer dune management away from the creation of landscapes that were highly modified by human influences to those where natural processes are much more influential. Particular emphasis was given to the benefits of restoring and promoting the near natural operation of geomorphological and other physical processes as desirable and formative forces of a dynamic environment. The event was recorded in the publication 'Perspectives in Coastal Dune Management' (Van der Meulen et al. 1989) and this dynamic approach to dune management. The dynamic approach to dune management is now well established in academic, professional and popular literature (Houston 1991 and 1997, Houston et al. 2001, Martinez and Psuty 2008) with a loose network for European coastal dune management and research in existence since the late1980s. This loose European network meets quite frequently at conferences and workshops, usually relying heavily on networks of individual contacts.

The UK Sand Dune and Shingle Network was established in 2006 and aims to address the gap between thinking and practice. It supports the sustainable management of these habitats, encourages an exchange of information and experience and assists the development of links between different interests. Through the 'Changing Perspectives in Coastal Dune Management' 2008 conference the network aimed to support the development of networks and communities of practice, not only as networks of individuals but also of concepts and theories. In Europe since 2006 we have experienced calls to develop dune networks beyond the UK, with particular progress made in the areas of the Belgian / Dutch coast, the Iberian Peninsula, Italy and the Baltic coast. As the dune network concept develops we hope that it may grow in to a European dune meta-network, with national networks and local 'subnets' forming communities of practice. Multiple communities (e.g. sectors such as engineers, foresters and the golf industry) may be nested with a larger network and through the creation of 'boundary objects' such as inter-disciplinary meetings, key publications and joint project working between these communities may be sensitised to alternative practices and lead to realigned perspectives. Whatever develops, the initiative must remain firmly habitat based and participants should check regularly that they have 'sand in their pockets'.

The papers arising from the 'Changing Perspectives in Coastal Dune Management' conference bring us back to the requirement to have a sound evidence base to inform our management of coastal dunes.

Provoost et al provide an overview of changes in the landscape and vegetation of coastal dunes in north west
Europe over the last century. The authors highlight that landscape change is a rule, rather than exception, for coastal dunes and discuss the causes of this change. The major issues faced by dune conservationists are raised: that the biodiversity of open and early succession dunes is highly valued and that recent trends towards senescence through a reduction of anthropogenic influences threaten this, and that scrub and woodland development resulting from this change deserves more attention. Perhaps this development of scrub and woodland may modify our perspectives on the biodiversity values of coastal dunes? Finally, the paper sets out some implications and challenges for dune management, including the re-mobilisation of stable, senescent dunes.

The paper by Weeda considers alien plant species in the Dutch coastal dune vegetation. Interestingly, this paper considers archaeophytes, long established introduced nonnative plants, which are now often viewed as accepted and familiar components of the dune vegetation. Weeda also raises the issue of neophytes, newly introduced plant species. These are often the focus of attention for dune managers, but include the issue of Campylopus introflexus, an invasive perennial moss that forms dense mats. This moss is very probably overlooked by many dune managers.

Barrett-Mold and Burningham present a study from the north west coast of Ireland investigating the influence of morphological evolution of dunes on plant species diversity. Through detailed study of the Magheramore system they highlight the importance of dynamic geomorphic processes to sustain the natural values of coastal dune systems. This is an important guiding principle for all involved in the management of dunes.

The importance of coastal dunes for terrestrial invertebrates in Wales and the UK is presented in the paper by Howe et al. This paper describes some uninviting implications for terrestrial invertebrates of an increasing trend of reduced mobility and amount of bare sand in dune systems. The authors challenge some of the grazing management techniques used in coastal dune management, and indicate a need for radical action to re-mobilize at least the key sand dune systems.

The role of rabbit grazing and its effects on vegetation, soil and microclimate on the German island of Nordeney are researched in the paper by Isermann. The study employs the straightforward, yet highly effective, technique of grazing exclosures set out in a variety of dune habitat types. The results of the study strengthen our understandings of how the effects of grazing vary with dune habitat type. The rabbit is most certainly one of the most important drivers that has shaped the vegetation and landscape of European dunes and as such deserves sustained attention in dune conservation management.

In the UK, long term data sets recording variations in dune groundwater levels are scarce. Clarke presents a paper 
analysing groundwater levels recorded between 1972 and 2007 at Ainsdale Sand Dunes National Nature Reserve on the Sefton Coast, north west England. The study site is partially forested with pine plantations. Clarke presents data on the negative impact of pine plantations on dune groundwater levels. He focuses on dune slacks and predicts the effects of climate change on groundwater levels in the dune system. This paper presents important messages for dune managers indicating the need to prioritise their actions in the face of climate change impacts.

Jones et al present two papers in this Special Issue. The first considers factors affecting vegetation establishment and development at Newborough Warren, north Wales. This study discusses the role of climate in vegetation development and how the maintenance of some areas of open sand is important for a dynamic dune system. The study suggests that dune managers can only operate within the limits of natural climatic conditions. This is a crucial point for those designing and proposing dune restoration / rehabilitation schemes. The second paper by Jones et al describes an innovative management technique of topsoil inversion using deep ploughing as a restoration measure in dunes. Although the results of this trial are only partially successful, the creativity to employ techniques that attempt to address shared problems in coastal dune management is highly commended.

Finally, the paper by Psuty steps back from the fine detail of conservation management practice to address climate change as the big issue of the day for coastal dunes. The paper argues that climate change may be an opportunity for coastal dunes as it may lead to positive or equilibrium sediment budgets in coastal foredunes and the retention of the foredune system even as it is being replaced. Psuty argues that for this to occur accommodation space is required. Therefore the paper identifies the need for planning to influence management practice, and as such complements the title of this Journal.

Each of the papers presented in this Special Issue of JCCPM value the properties of a dynamic dune system. Guidance is provided for those tasked with coastal dune management including that, while working within the possible limits of climate, management actions should wherever possible work at the geomorphological level.

Many thanks go to all the authors and reviewers who contributed to this Special Issue. Particular thanks go to John Houston and Sally Edmondson of Liverpool Hope University, and David Green, Editor-in-Chief of this publication. Without their help and patience the conference and Special Issue of this journal would not have been possible.

\section{References}

Houston J (1991) Blowing in the wind. Landscape Design 206:25-29 Houston J (1997) Conservation management practice on British dune systems. British Wildlife 8(5):297-307

Houston JA, Edmondson SE, Rooney PJ (eds) (2001) Coastal dune management. Shared experience of European conservation practice. Liverpool University Press

Martinez ML, Psuty NP (eds) (2008) Coastal dunes, ecology and conservation. Springer-Verlag

Ranwell DS (1972) Ecology of salt marshes and sand dunes. Chapman and Hall

Rooney P, Houston J (2009) From wasteland to joy land.-changing attitudes to coastal dunes. Ecos-A Review of Conservation 30 (2): $50-57$

Salisbury E (1952) Downs and dunes. G. Bell and Sons Ltd

Steers JA (1946) The coastline of England and Wales. Cambridge University Press

Van der Meulen F, Jungerius PD, Visser JH (eds) (1989) Perspectives in coastal dune management. SPB Academic 